\title{
Forum International au Sahel sur l'Éducation
} Environnementale

25 - 29 octobre 1999- Nouakchott (Mauritanie, Afrique de l'Ouest)

\section{Moussa Batchily Ba}

\section{OpenEdition}

\section{Journals}

Édition électronique

URL : http://journals.openedition.org/ere/6887

ISSN : 2561-2271

Éditeur

Centr'ERE

Référence électronique

Moussa Batchily Ba, « Forum International au Sahel sur l'Éducation Environnementale », Éducation relative à l'environnement [En ligne], Volume 2 | 2000, mis en ligne le 15 septembre 2000, consulté le 17 avril 2021. URL : http://journals.openedition.org/ere/6887 


\title{
Forum International au Sahel sur l'Éducation Environnementale
}

\author{
25 - 29 octobre 1999- Nouakchott (Mauritanie, Afrique de l'Ouest)
}

Moussa Batchily Ba

1 Le Comité Permanent Inter-États de Lutte contre la Sécheresse au Sahel (CILSS) a organisé en partenariat avec la Commission Européenne et à travers le PFIE (Programme de Formation et d'Information sur l'Environnement) le Forum International au Sahel sur l'Éducation Environnementale (FISEE).

2 Venant d'horizons divers, décideurs, spécialistes, formateurs, éducateurs et élèves, hommes et femmes de la communication ont convergé au rendez-vous de «la Planète en Partage ». Le Sahel s'est fait l'écho du Forum Planèt'ERE de Montréal (1997) et l'annonce de l'Odyssée 2001 en France.

3 Un demi-millier de participants réunis à Nouakchott (République Islamique de Mauritanie) ont tenu à marquer de leur présence leur adhésion au Forum International au Sahel sur l'Éducation Environnementale. Pari osé que de regrouper tout ce monde autour d'un sujet de préoccupation mondial depuis sa consécration à Rio en 1992. Pari audacieux pour montrer au reste de la communauté internationale les résultats et besoins de l'éducation environnementale au Sahel. Pari sur l'avenir, comme l'ont écrit et dit les enfants «aux autres enfants du monde, nous tendons la main pour garder saine et accueillante notre planète ".

4 Le FISEE a été organisé sous le slogan " la Planète en Partage ». Le besoin était grand chez les Sahéliens de marquer leur entrée dans le troisième millénaire et d'inviter la communauté internationale au partage. Cette notion de solidarité est importante si l'on admet que les questions d'environnement ne connaissent pas de frontières. Échanger et partager, renforcer les liens de coopération et réfléchir à de nouvelles stratégies d'engagement étaient au nombre des résultats affichés par le FISEE. Rapportons ce geste de solidarité des caravaniers qui face aux inondations subies par la ville de SaintLouis ont contribué, de façon symbolique, par l'envoi d'une enveloppe financière pour aider les écoles inondées. 
5 Un rapport et un documentaire filmé sont consacrés au FISEE pour fixer dans les mémoires tout ce qui s'est passé. L'ouverture, à l'Université de Nouakchott, par le premier ministre de Mauritanie, a été marquée par la parole des enfants. Ensuite, différents moments forts: le parlement des enfants où, endossant les habits du législateur, ils ont développé un véritable plaidoyer pour l'environnement; la caravane de solidarité mondiale pour l'environnement regroupant plus de 200 personnes entre Dakar et Nouakchott; le campement écologique et la plantation d'arbres de l'espoir. Enfin, une activité importante : la table ronde des ministres; les communications et les stands, les ateliers pédagogiques des enfants et des adultes; et tout simplement les visites de sites de Nouakchott. Autant d'images fortes qui défilent dans nos têtes et dont rendra compte un documentaire filmé bientôt disponible.

6 Les résultats du FISEE sont donc importants : des engagements forts, individuels et collectifs; l'implication d'une part importante de la société civile : la jeunesse; mais également un engagement institutionnel assurant la pérennisation de l'éducation environnementale; enfin des engagements collectifs avec une implication d'un partenariat mondial pour l'environnement : l'Odyssée 2001 en France a été préparée.

7 Nous devons attacher un prix élevé à la mise en oeuvre de la déclaration de Nouakchott, au message des enfants et à la résolution des ministres.

8 Il est à espérer qu'à travers le film et le rapport certains diront «nous étions présents »; d'autres «nous aurions voulu être de la partie»; d'autres encore "nous serons encore plus nombreux à l'Odyssée 2001, en France ».

\section{AUTEUR}

\section{MOUSSA BATCHILY BA}

Institut du Sahel 